\title{
Synthesis of potentially biobased poly(hexamethylene sebacate) via reactive extrusion
}

\author{
Bastien Turlier $^{\mathrm{a}, \mathrm{b}}$, Jérôme Gimenez ${ }^{\mathrm{c}}$, Laurent Goujard ${ }^{\mathrm{c}}$, Alain Rousseau ${ }^{\mathrm{b}}$, Noëllie Ylla ${ }^{\mathrm{a}}$, \\ Véronique Bounor-Legaré ${ }^{\mathrm{a}}$, Françoise Fenouillot ${ }^{\mathrm{b}, *}$
}

${ }^{a}$ Univ Lyon, Université Lyon 1, CNRS, IMP UMR 5223, Ingénierie des Matériaux Polymères, F-69622, Lyon, France

${ }^{\mathrm{b}}$ Univ Lyon, INSA Lyon, CNRS, IMP UMR 5223, Ingénierie des Matériaux Polymères, F-69621, Villeurbanne, France

${ }^{\mathrm{c}}$ Setup Performance, 10 route du Chaffard, F-38290, Frontonas, France

\section{A R T I C L E I N F O}

\section{Keywords:}

Reactive extrusion

Polyester

poly(hexamethylene sebacate)

Esterification

Polycondensation

\begin{abstract}
A B S T R A C T
The synthesis of a biobased aliphatic polyester, poly (hexamethylene sebacate) (PE 6-10) via esterification and alcoholysis reaction steps by reactive extrusion is reported. The overall reaction time was decreased down to around $14 \mathrm{~min}$ instead of roughly $360 \mathrm{~min}$ in a classical batch reactor. A number average molar mass of 21,100 g. $\mathrm{mol}^{-1}$ has been reached. The operating conditions were first optimized through batch reactors syntheses. More specifically, two catalysts have been selected: para-toluenesulfonic acid (PTSA), essential for carrying out the esterification in a time compatible with extrusion residence time, and $n$-butylhydroxyoxostannane $(\mathrm{BuSnOOH})$ necessary for the activation of alcoholysis reactions. The reactive extrusion process may therefore be very promising for the research and development of new polyesters and copolyesters in a fast and flexible continuous process.
\end{abstract}

\section{Introduction}

Reactive extrusion process has been tested with more or less success as a polymerization reactor for polycondensates synthesis. Polyurethanes were synthesized quite easily since diol/isocyanate reaction is very fast $[1,2]$. High molar masses were produced in a very short time and weight average molar mass (Mw) around 100,000 g.mol ${ }^{-1}$ were obtained in 2-8 $\mathrm{min}$ [3].

Activated anionic polymerization of lactams is fast enough to be processed in extruders [4]. In 2 min, Wollny et al. obtained polyamide 12 with number average molar mass $(\mathrm{Mn})$ ranging from 15,000 to 19 , 000 g.mol ${ }^{-1}$ and then compounded blends in a single extrusion step, lauryl lactam acting as a reactive solvent [5]. Polyamide 6 was also synthesized by Hornsby et al. Residual monomer was present at 4-7\% and $\mathrm{Mn}$ was between 16,000 and 19,000 g.mol ${ }^{-1}$ [6]. Yan et al. polymerized epsilon-caprolactam with dissolved polystyrene in extruder to form oriented micro-composites in one extrusion stage [7].

The synthesis of A-A + B-B polyamides is much trickier because reactions are slower. Only a few studies may be found. As an example, Desbois et al. used a twin-screw micro-extruder as reactor for terephthalic acid and hexamethylene diamine polycondensation [8]. They fed the extruder with a solid mixture of monomers in the salt form to obtain polyamides with a viscosity in solution between 20 and $30 \mathrm{~mL} . \mathrm{g}^{-1}$ in 1-20 min. The technique was only established with a micro extruder where the reaction time can be easily tuned. This last point is important since the process differed drastically from industrial extruders. The synthesis of polyamides in industrial twin-screw extruders was performed by Lagneaux et al. and is summarized in their patent [9]. The diacid and diamine monomers were introduced into the extruder without prior treatment. The monomer feed rate was varied between 2 and $480 \mathrm{~kg} \mathrm{~h}^{-1}$. The residence times were in the range 5-20 min. The polymers had reduced solution viscosities between 80 and $180 \mathrm{~mL} . \mathrm{g}^{-1}$ depending on aliphatic or semi-aromatic nature of the polyamide.

Recently the synthesis of polyimides was reported by Verny et al. [10]. The authors compared bulk polymerization with micro and laboratory twin-screw extruders. The monomers were pyromellitic dianhydride (PMDA) or 3,3',4,4'-benzophenone tetracarboxylic dianhydride (BTDA) associated with a diamine Jeffamine D. The imidization kinetics were compatible with extrusion since nearly $100 \%$ conversion was attained in less than $5 \mathrm{~min}$ in a range of temperature between 180 and $225{ }^{\circ} \mathrm{C}$. Mn ranged between 11,000 and 14,000 g. mol ${ }^{-1}$ depending on the systems and synthesis processes.

\footnotetext{
* Corresponding author.

E-mail address: Francoise.Fenouillot@insa-lyon.fr (F. Fenouillot).
} 
If we come back to polyesters, several studies were published on ringopening polymerization that is fast and well adapted to extrusion [11, 12]. For example, the literature describes how to synthesize and modify poly (lactic acid) by extrusion [13,14]. Polycaprolactone is also a good candidate to be polymerized in extruders [15-17]. Omega-pentadecalactone enzymatic polymerization studied by Spinella et al. is a very interesting example showing how high mixing ability of the extruder permits to attain very high molar mass $(\mathrm{Mn}=80,000 \mathrm{~g}$. $\mathrm{mol}^{-1}$ ) with less immobilized lipase catalyst that for batch process $\left(\mathrm{Mn}=20,000 \mathrm{~g} \cdot \mathrm{mol}^{-1}\right)$ [18]. Cyclic poly (butylene terephthalate) oligomers polymerize in a few minutes and may be used in extruders in order to produce blends and copolymers [19,20].

For the classical synthesis route of polyesters by esterification and/or exchange reactions, one of the very few publications found is the work of Gouinlock et al. published in 1968 [21]. The authors synthesized a copolymer from bisphenol A, neopentyl glycol and terephthaloyl chloride. They have preliminary synthesized oligomers in a batch reactor (intrinsic viscosity of $0.16 \mathrm{dL} \cdot \mathrm{g}^{-1}$ ) which they injected into the extruder in order to increase the molar mass. The oligomers were introduced into a co-rotating twin-screw extruder with length/diameter $=37$ and a diameter of $20.3 \mathrm{~mm}$. The extruder was equipped with vents and one of them allowed to inject nitrogen to carry out the vapors and put the medium under an inert atmosphere. One of the vents was used for degassing the volatiles under a vacuum of 2.6-3.3 mbar. The feed rate was $0.3-0.6 \mathrm{~kg} . \mathrm{h}^{-1}$ with screw speed ranging from 50 to $100 \mathrm{rpm}$. The residence time in the extruder was between 15 and $30 \mathrm{~min}$. A thermal stabilizing additive, triphenylphosphine was introduced in this case in order to limit the degradation of the polymer. With the optimized method, the authors were able to increase the intrinsic viscosity to a value of $0.73-0.76 \mathrm{dL} . \mathrm{g}^{-1}$, demonstrating that it was possible to use an extruder to form a polyester. However, the synthesis was not totally carried out in an extruder because of the use of prepolymers.

More recently in 2009, Shogren et al. prepared branched or even partially crosslinked poly (sorbitol citrates) by reactive extrusion from sorbitol, citric acid and trisodium citrate dihydrate. The weight average molar mass obtained (Mw) were between 1000 and 26,000 g.mol ${ }^{-1}$ depending on the conditions and the residence time. The latter was between 1 and $5.5 \mathrm{~min}$. The authors report a possible catalytic effect of sodium ions. The conversion was rather low since the residual acid level was between 50 and $73 \%$ [22].

The lack of information on the synthesis of polyesters in an extruder by classical polycondensation process is not a surprise since it is a real challenge for several reasons:

- It proceeds by esterification or/and by exchange reactions that are relatively slow.

- These reactions are equilibrated and require that the volatiles byproducts (water, alcohol, diol) are to be eliminated in a very efficient and continuous manner from the reactive medium.

- These reactions may also need accurate control of the stoichiometry of the reagents.

For these reasons it takes typically several hours reaction time and very high vacuum to obtain high weight average molar mass polyesters in a typical batch or continuous industrial reactor. The appropriate conditions are very difficult to achieve in an open reactor such as the extruder. The residence time in an extruder can hardly exceed 15-20 min and going to longer residence time is possible only by sacrificing the flow rate that will have to be extremely low. Degassing is possible but very low pressures are difficult to maintain. These difficulties explain that scientific literature is scarce since success rarely comes.

In this context, the objective of this work was to determine under which conditions a twin-screw extruder could be a continuous reactor able synthesizing thermoplastic polyester by esterification and/or exchange reactions. A second goal was to specify the scope and the limits of the technique. For this purpose, the polymerization conditions were determined using batch reactors and adapted for twin-screw extrusion reactive processing.

A model aliphatic polyester was chosen, poly (hexamethylene sebacate) (PE 6-10). The choice of poly (hexamethylene sebacate) was guided first by considering the properties of its monomers. Sebacic acid and 1,6-hexanediol have a high boiling point, higher than $200{ }^{\circ} \mathrm{C}$ at atmospheric pressure. This is favorable for the extrusion process because it helps controlling the stoichiometry by limiting monomer evaporation. Second, the very simple structure of PE 6-10 polyester and its solubility in different solvents allows a detailed and quantitative analysis of its structure by ${ }^{1} \mathrm{H}$ NMR spectroscopy. The renewable and biodegradable nature of PE 6-10 were also good points in the scope of moving toward more environmentally friendly processes approaches. Sebacic acid may be derived from castor oil and 1,6-hexanediol can be obtained by degradation and reduction of hemicellulose [23,24]. PE 6-10 is semi-crystalline with a melting point of $67^{\circ} \mathrm{C}$ [25-27]. This polyester is biodegradable and easily hydrolyzed in soil. Its constitutive monomers are also totally biodegraded in soil and $30-50 \%$ of their carbon is converted to biomass [28].

\section{Experimental part}

\subsection{Monomers and reagents}

1,6-Hexanediol monomer (99\%) was supplied by BASF and sebacic acid monomer (99\%) was supplied by Sabic. $n$-Butylhydroxyoxostannane (BuSnOOH) was purchased from TCI Europe N.V., $p$-Toluenesulfonic acid $(>98 \%)$ was purchased from Sigma-Aldrich. All chemicals were used as received without further purification.

\subsection{Small scale esterification reactor}

A stainless steel reactor with a capacity of $500 \mathrm{~mL}$ was used to optimize the esterification. It was equipped with a stirrer and a condenser that allows collecting the water produced by the reaction. Monomers and catalysts were introduced into the reactor at room temperature. The quantity introduced was approximately $100 \mathrm{~g}$. A nitrogen atmosphere with the desired pressure was established. The stirring speed was set as $100 \mathrm{rpm}$. The esterification conversion was determined by ${ }^{1} \mathrm{H}$ NMR spectroscopy on small samples of the reactive medium collected during the reaction and frozen (supporting information). The synthesized polymer was recovered via the opening of a bottom valve located under the reactor. This valve was thermally regulated. All measurements, namely the reactor temperature, the temperature of the reactive medium, the temperature of the bottom valve, the pressure in the reactor and the mechanical torque of the stirrer motor were recorded continuously.

\subsection{Esterification-polycondensation in $7.5 \mathrm{~L}$ pilot reactor}

A second reactor was used to optimize the polycondensation step. It was a 7.5 L stainless steel batch reactor equipped with a mechanical stirrer with torque measurement, a distillation column, a vacuum line and a nitrogen gas inlet $[29,30]$. The reactor was charged with $10 \mathrm{~mol}$ of sebacic acid and $10 \mathrm{~mol}$ of hexanediol ( $\sim 2.8 \mathrm{~kg}$ of final polyester). The amount of hexanediol was adjusted depending on the diacid/diol ratio. The esterification catalyst was introduced at this stage. Catalyst quantity was calculated as the mass of metallic element to the theoretical polymer quantity. The reaction mixture was heated to the desired temperature under a 2 bars nitrogen pressure and stirred at $300 \mathrm{rpm}$. The esterification conversion was estimated continuously by weighing the water distillate collected. When necessary, the oligomers obtained after the esterification where sampled for analysis.

The introduction of the polycondensation catalyst was done after decompression at atmospheric pressure. The pressure was then reduced from atmospheric pressure to $0.5 \mathrm{mbar}$ in $90 \mathrm{~min}$ to initiate the 
polycondensation step. Different temperatures have been tested from 230 to $250{ }^{\circ} \mathrm{C}$. Low pressure conditions were maintained until reaching the desired torque increase measured by the stirrer $(\Delta \mathrm{C})$ or until a certain time. The initial time, $t=0$, of polycondensation started when the vacuum ramp was initiated.

The final polymer strand was withdrawn from the bottom drain valve of the reactor, quenched in a water bath and pelletized. White crystalline PE 6-10 pellets were obtained.

\subsection{Reactive extrusion}

The first machine dedicated to the esterification reaction optimization was a co-rotating twin-screw extruder TSA with a diameter of 26 $\mathrm{mm}$ and an $\mathrm{L} / \mathrm{D}$ ratio equal to 80 . It had vents at each $5 \mathrm{D}$ except for 10 , 25,50 and $80 \mathrm{D}$. A side feeder could be positioned at $20,30,40,60,65$ or 70D. The elimination of the volatile by-products of the reaction was ensured by opening the vents or through the screw of the side feeder. A thermoregulated vertical feeder was set up on one of the vents. By this means, it was possible to condense the diol in the vertical feeder and reinject it in order to compensate partially its loss.

The diacid was introduced as a solid powder with a gravimetric micro-feeder. The diol was stored in a vessel thermoregulated at $170{ }^{\circ} \mathrm{C}$ and connected to a high precision gear pump with flow rate from $0.3 \mathrm{~kg}$. $\mathrm{h}^{-1}$ to $15 \mathrm{~kg} \cdot \mathrm{h}^{-1}$. The control of the flow rates of the monomers was possible with an accuracy of $0.1 \mathrm{wt} \%$.

The second machine dedicated to the polycondensation was a Leistritz co-rotating twin-screw extruder $18 \mathrm{~mm}$ diameter with an $\mathrm{L} / \mathrm{D}$ ratio of 60 . This extruder was equipped with a side feeder positioned at $17 \mathrm{~L} /$ $\mathrm{D}$ acting as a condenser. The reagent introduction system for this $60 \mathrm{D}$ extruder was composed of a set of two thermally regulated tanks connected to high precision gear pumps and able to accept a flow rate from $0.3 \mathrm{~kg} \cdot \mathrm{h}^{-1}$ to $15 \mathrm{~kg} \cdot \mathrm{h}^{-1}$. The setpoint temperature used for oligomers was $165^{\circ} \mathrm{C}$.

\subsection{Characterizations}

The oligomers and polymers characteristics (Esterification conversion, Mn, chain ends concentration) were determined by ${ }^{1} \mathrm{H}$ NMR spectroscopy. Molar masses and dispersity were determined by Size Exclusion Chromatography (SEC) when needed.

Characterization methods and the determination of esterification and number average molar mass with ${ }^{1} \mathrm{H}$ NMR spectroscopy are summarized in the supporting information. An example of a typical ${ }^{1} \mathrm{H}$ NMR spectrum of PE 6-10 is shown in Figure S1 of the supporting information.

\section{Results and discussion}

\subsection{Optimization of the experimental conditions through batch reactor synthesis}

Thermoplastic polyesters are most often synthesized by the acidic route (Fig. 1). The first step is the esterification of an excess of diol with the diacid to obtain oligomers which are predominantly terminated by alcohol functions. Water is eliminated. Then a polycondensation step is carried out under vacuum in the presence of a catalyst to activate alcoholysis reactions and grow the chains. Effective alcoholysis occur between the hydroxyl and esters end-groups. Diol is released and removed under vacuum to shift the equilibrium toward chain growth. This strategy makes it possible, among other advantages, to free up from

\begin{tabular}{lccc}
\hline Monomers & $\mathbf{M}\left(\mathrm{g} \cdot \mathrm{mol}-{ }^{-1}\right)$ & $\mathrm{T}_{\mathrm{m}}\left({ }^{\circ} \mathrm{C}\right)$ & $\mathrm{T}_{\mathrm{b}}\left({ }^{\circ} \mathrm{C}\right)$ \\
\hline 1,6-Hexanediol & 118.17 & 40 & 250 \\
\hline 1,8-Decanedioic acid (Sebacic acid) & 202.25 & 134 & 295 (at 133 mbar) \\
\hline
\end{tabular}

(a) Esterification

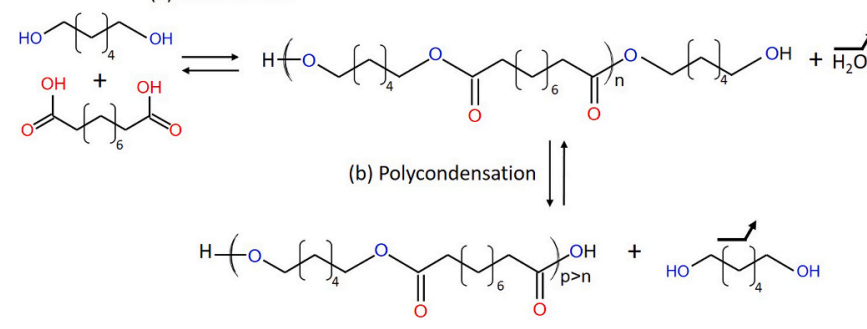

Fig. 1. Properties of the monomers and poly (hexamethylene sebacate) (PE 610) synthesis steps. a) Esterification of sebacic acid with 1,6-hexanediol in excess. b) Alcoholysis of PE 6-10 chain-end diol ester by hydroxyl end-groups of the oligomers, and resulting poly (hexamethylene sebacate) (PE 6-10).

the need of a perfect control of the stoichiometric ratio in alcohol and acid functions. The method was adopted for the batch reactor study to optimize the synthesis parameters of PE 6-10 and transfer them to the reactive extrusion process.

The choice of the catalysts is of importance. The work of O'Malley and Stauffer is an example of the use of para-toluenesulfonic acid (PTSA), a typical catalyst for esterification, for the synthesis of PE 6-10 [26]. The authors have synthesized oligomers with an excess of $10 \mathrm{~mol} \%$ of diol and 5,000 ppm of PTSA relative to the overall mass of the monomers. They obtained oligomers with a number average molar mass of 2,400-5,400 g. $\mathrm{mol}^{-1}$ in $4.5 \mathrm{~h}$ at $165^{\circ} \mathrm{C}$.

Other catalysts have also been employed for the synthesis of this polyester such as transition metal based Lewis-acids. The catalyst used by Erhardt was lead acetate, which is an excellent esterification catalyst but is now banned [31]. Armelin et al. used titanium tetrabutoxide for their synthesis of PE 6-10 with a molar excess of hexanediol (alcohol/acid molar ratio=2.2/1) [27]. A patent by Farachi et al. reports $n$-butylhydroxyoxostannane acid (BuSnOOH) as a catalyst (300 ppm of tin element). The molar mass of the oligomers was not given. The authors continue the synthesis to increase the molar masses and form a PE 6-10 with intrinsic viscosity of $1.3 \mathrm{dL} \cdot \mathrm{g}^{-1}$ [32].

\subsubsection{Esterification reaction}

The objective was to characterize esterification kinetics. The diol to diacid molar ratio was fixed to 1 . The parameters studied were the temperature, the nature of the catalyst and its proportion. Three catalysts were tested: $n$-butylhydroxyoxostannane acid (BuSnOOH), paratoluenesulfonic acid (PTSA) and enzymatic lipase catalysts (Novozim 435 and PS Amano SD). BuSnOOH had no catalytic activity on esterification and the enzymatic catalysts were not active enough. Only the PTSA has given satisfactory results and is presented here.

Fig. 2 shows the esterification conversion evolution measured in the laboratory reactor at three different temperatures $\left(150,185\right.$ and $\left.230^{\circ} \mathrm{C}\right)$ without catalyst and when using $10,000 \mathrm{ppm}$ of PTSA relative to the theoretical mass of recovered polyester. The reaction started earlier and there was a clear acceleration with the addition PTSA. Several concentrations were tested and a large amount of PTSA was necessary to get a conversion higher than $85 \%$ in 30 min. Oligomers with a Mn ranging from 260 to 2,300 g.mol ${ }^{-1}$ were obtained depending on the synthesis conditions (Table 1 ). 


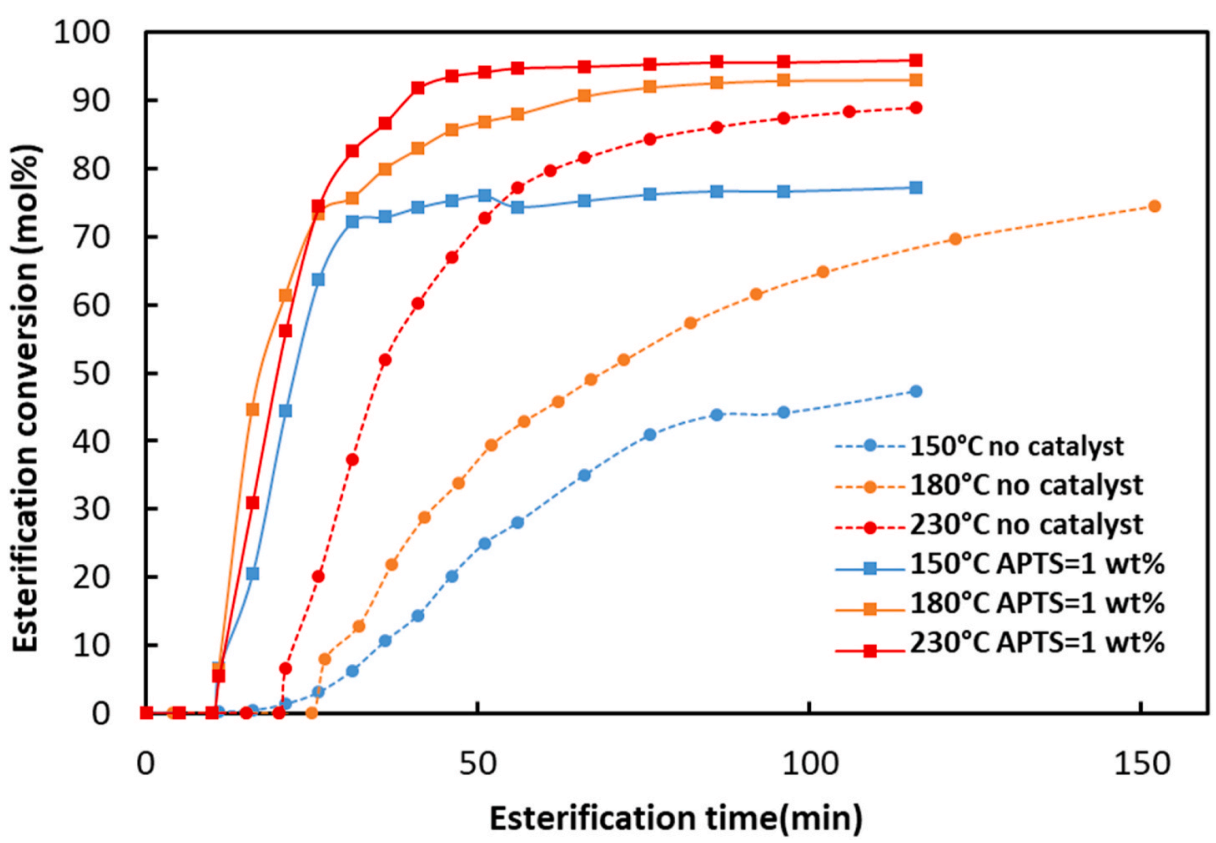

Fig. 2. Evolution of the esterification conversion versus time during synthesis of PE $6-10$ with diacid/diol $=1$. Without catalyst and with 10,000 ppm of PTSA. $T=$ 150,185 and $230{ }^{\circ} \mathrm{C}$.

Table 1

Data obtianed after $120 \mathrm{~min}$ esterification in the laboratory reactor with diacid/ diol $=1$ without catalyst and with $10,000 \mathrm{ppm}$ of PTSA catalyst at $\mathrm{T}=150,185$ et $230{ }^{\circ} \mathrm{C}$.

\begin{tabular}{ccccc}
\hline $\begin{array}{c}\text { Temperature } \\
\left({ }^{\circ} \mathrm{C}\right)\end{array}$ & $\begin{array}{c}\text { PTSA } \\
(\mathrm{ppm})\end{array}$ & $\begin{array}{c}\text { Esterification } \\
\text { yield }(\mathrm{mol} \%)\end{array}$ & $\begin{array}{c}\text { Mn of the } \\
\text { oligomers }^{\mathrm{a}}(\mathrm{g} . \\
\left.\mathrm{mol}^{-1}\right)\end{array}$ & $\begin{array}{c}\text { Chain ends } \\
{[\mathrm{COOH}] /} \\
{[\mathrm{OH}]}\end{array}$ \\
\hline 150 & 0 & 47 & 258 & 1 \\
& 10,000 & 77 & 600 & 1 \\
\hline 185 & 0 & 70 & 440 & $1.42^{\mathrm{b}}$ \\
& 10,000 & 93 & 1,740 & 1.36 \\
\hline 230 & 0 & 89 & 1,420 & 1.08 \\
& 10,000 & 96 & 2,270 & 1.99 \\
\hline
\end{tabular}

${ }^{\text {a }}$ Determined by ${ }^{1} \mathrm{H}$ NMR spectroscopy (see supporting information).

b Reaction time $=155 \mathrm{~min}$.

\subsubsection{Polycondensation}

The polycondensation step was carried out on the $7.5 \mathrm{~L}$ pilot reactor which allows a good control of the pressure and of the vacuum ramp. The end time of the polycondensation was decided either when a stirring torque increase of $\Delta \mathrm{C}=15 \mathrm{~N} . \mathrm{m}$ was exceeded, or after $280 \mathrm{~min}$. When the polymerization started but was too slow or ineffective, we prematurely stopped the test and in this case the end time is indicated. The first step of esterification was also carried out on this reactor but only the results of the second step, beginning at $t=0$ when pressure was decreased are presented. Dibutyl tin oxide, tin octanoate, germanium oxide, antimony oxide and titanium compounds have been tested as alcoholysis catalysts, but gave unattractive results, they will not be presented here. We summarize only the results obtained with the most efficient catalyst in our case: $n$-butylhydroxyoxostannane acid (BuS$\mathrm{nOOH}$ ) associated in one case with PTSA.

Four parameters were varied: temperature, the nature and amount of catalyst and the initial ratio of alcohol and acid groups. Table 2

Table 2

Results of polycondensation experiments in the $7.5 \mathrm{~L}$ pilot reactor.

\begin{tabular}{|c|c|c|c|c|c|c|}
\hline Catalyst & $\mathrm{T}\left({ }^{\circ} \mathrm{C}\right)$ & $\begin{array}{l}\text { Monomers molar } \\
\text { ratio in feed } \\
{[\mathrm{COOH}] /[\mathrm{OH}]}\end{array}$ & $\begin{array}{c}\text { Oligomers } \\
\mathrm{Mn}\left(\mathrm{g} \cdot \mathrm{mol} \mathrm{l}^{-1}\right) \\
\text { and }[\mathrm{COOH}] /[\mathrm{OH}]\end{array}$ & Poly time $\mathrm{e}^{\mathrm{b}}(\mathrm{min})$ & $\begin{array}{c}\text { Final PE } 6-10^{c} \\
\text { chain ends ratio } \\
{[\mathrm{COOH}] /[\mathrm{OH}]}\end{array}$ & $\begin{array}{l}\text { Final PE } 6-10^{c} \\
\text { Mn }\left(\mathrm{g} \cdot \mathrm{mol}^{-1}\right)\end{array}$ \\
\hline No catalyst & 250 & $1 / 1$ & $1,400 / 0.92$ & 280 & 1.77 & 6,800 \\
\hline $\mathrm{BuSnOOH}(\mathrm{Sn}=300 \mathrm{ppm})$ & $\begin{array}{l}230 \\
250 \\
275\end{array}$ & $1 / 1$ & $\begin{array}{c}1,300 / 0.3 \\
2,100 / 0.88 \\
2,000 / 0.87\end{array}$ & $\begin{array}{l}280 \\
250 \\
125\end{array}$ & $\begin{array}{c}0.78 \\
0.86 \\
8\end{array}$ & $\begin{array}{l}35,000 \\
43,500 \\
31,500\end{array}$ \\
\hline $\begin{array}{l}\text { PTSA } 300 \text { ppm }+ \\
\text { BuSnOOH (Sn } 300 \text { ppm) }\end{array}$ & 250 & $1 / 1$ & $2,200 / 0.54$ & 260 & 0.14 & 35,000 \\
\hline
\end{tabular}

a The oligomers are obtained after the esterification step.

b The polycondensation time starts when the vacuum ramp is initiated (pressure lower than atmospheric pressure).

${ }^{\mathrm{c}}$ Determined with ${ }^{1} \mathrm{H}$ NMR spectroscopy. 
summarizes the main results and highlights the optimized process on the batch reactor.

Experiments at 230,250 and $275{ }^{\circ} \mathrm{C}$ have shown that a temperature of $250{ }^{\circ} \mathrm{C}$ was a good compromise, with a high molar mass obtained and low degradation. At $275{ }^{\circ} \mathrm{C} \mathrm{Mn}$ was lower and the chain ends ratio $[\mathrm{COOH}] /[\mathrm{OH}]=8$ indicates a majority of acid terminations and therefore significant degradation.

Concerning the effect of the catalyst, the molar masses obtained with and without PTSA in the presence of tin are close. Note that with PTSA, the overall reaction time was reduced. Actually respectively $35,000 \mathrm{~g}$. $\mathrm{mol}^{-1}$ and 43,500 g.mol ${ }^{-1}$ (for 20 min longer polycondensation time) are obtained. It is interesting then to use these two catalysts together. Notice that only $300 \mathrm{ppm}$ of PTSA were necessary in the pilot reactor probably because stirring and water distillation are much more efficient that in the small lab reactor.

The molar ratio of alcohol and acid was also an important parameter. This factor is affecting strongly the mechanisms by which chains are growing. Generally, a ratio $[\mathrm{COOH}] /[\mathrm{OH}]$ equal or lower than 1 (stoichiometry of reactive groups or excess of diol) is used because esterification and alcoholysis reactions are much easier to perform than acidolysis one. One reason is that acidolysis releases the diacid that is almost impossible to degas from the reactor because of its high boiling point $\left(\mathrm{T}_{\mathrm{b}}=295{ }^{\circ} \mathrm{C}\right.$, under $133 \mathrm{mbar}$ for sebacic acid). When alcohol and acid groups are present at initial equal concentration, esterification and alcoholysis both participate to chain growth. On the other hand, when alcohol groups are initially in excess, esterification will be the main mechanism involved in the oligomers synthesis at the beginning of the process but then alcoholysis reactions will dominate. Esterification releases water that is very easy to remove from the reactive medium, while alcoholysis releases the diol which is a high boiling point molecule, more difficult to degas. This feature is important to keep in mind because the progress of the polymerization may be different depending on the evolution of alcohol and acid groups concentration.

We therefore seek to promote alcoholysis compared to other transreactions by using an excess of alcohol functions. An equimolar amount of monomers would also be very interesting in extrusion because both esterification and alcoholysis would be possible. At $\mathrm{T}=250{ }^{\circ} \mathrm{C}$, it was found that $[\mathrm{COOH}] /[\mathrm{OH}]=1$ gives the best result with $\mathrm{Mn}=43,500 \mathrm{~g}$ $\mathrm{mol}^{-1}$. The excess of $5 \mathrm{~mol} \%$ of diol was also interesting $(\mathrm{Mn}=26,500 \mathrm{~g}$. $\mathrm{mol}^{-1}$ ) while with a $10 \mathrm{~mol} \%$ diol excess the molar mass was lower $\left(\mathrm{Mn}=8,400 \mathrm{~g} \cdot \mathrm{mol}^{-1}\right)$. An excess of diacid has also been tested but the reaction did not progress, which was predictable because of the difficulties to eliminate this monomer.

Interestingly, the initial ratio acid/alcohol had a notable impact on the course of the polycondensation. This was noticeable when the stirring torque increase $(\Delta C)$, related to melt viscosity thus related to molar mass, was plotted as a function of time. The increase in torque was very different depending on whether the stoichiometry was 1 or with an excess of diol. In the case of an equimolar mixture, the torque increased very rapidly in the earlier times of reaction to slow down after $100 \mathrm{~min}$ of reaction whereas in the presence of diol excess, the torque increased first slowly and then after 100min of reaction very rapidly (Fig. 3). This feature means that the chain length evolution with time was different depending on the diol/diacid initial ratio.

Monitoring of the reaction was carried out to interpret this result. The course of the reaction was interrupted and the polyester collected for stirring torque values $\Delta \mathrm{C}$ of $0.2,5.8$ and $12.1 \mathrm{~N}$.m respectively. The average molar masses measured by SEC and $[\mathrm{COOH}] /[\mathrm{OH}]$ chain ends ratio are plotted versus time (Fig. 4) and data summarized in Table 3. In the case of the equimolar mixture of monomers $\mathrm{Mw}$ increased rapidly from the beginning of the polycondensation and then stagnated. For the diol excess Mw increased slowly, then rose up after 200 min (Fig. 4a). These evolutions are well consistent with those of the stirring torque. The evolution of chain ends ratio is also clearly different with high or very low acidic chain ends proportion depending on the initial ratio (Fig. 4b).

We propose the following hypothesis for this unexpected behavior:

- In the case of the initial equimolar proportion of acid and alcohol the esterification reactions are present and in competition with alcoholysis. Water is produced and is eliminated very effectively from the reaction medium especially under a low vacuum, causing the early growth of the chains. At $\mathrm{t}=65$ and $120 \mathrm{~min}$, the chain ends ratio $[\mathrm{COOH}] /[\mathrm{OH}]$ is 0.65 and 0.85 respectively and the polymerization proceeds possibly by both mechanisms. Then, at the end of the reaction, $[\mathrm{COOH}] /[\mathrm{OH}]$ increases and reaches 2 meaning that degradation reactions are favored, the molar mass is stable and the polymerization time is very high ( $>350 \mathrm{~min}$ ).

- In the case of $5 \mathrm{~mol} \%$ initial diol excess, we have a very different situation. The chain ends ratio $[\mathrm{COOH}] /[\mathrm{OH}]$ is much lower, between 0.02 and 0.11 so the alcoholysis reactions dominate versus low contribution of the esterification reaction. Hexanediol is mainly

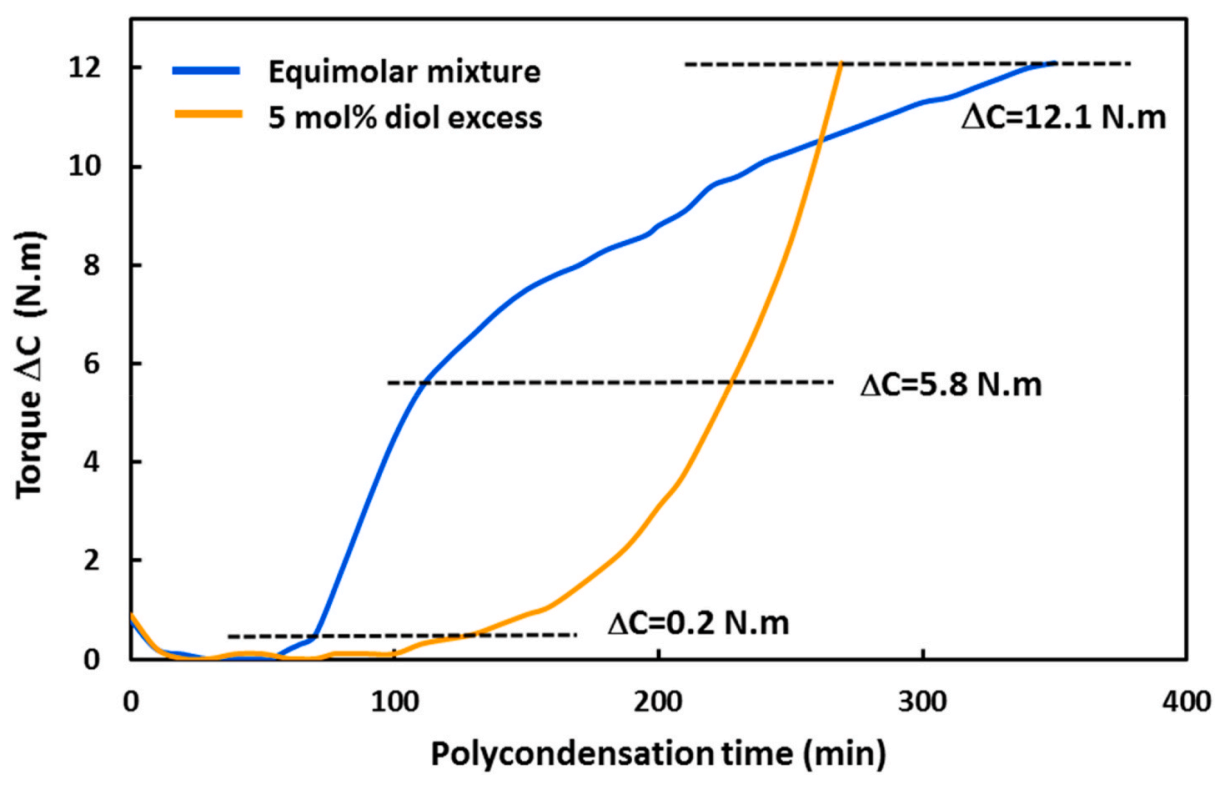

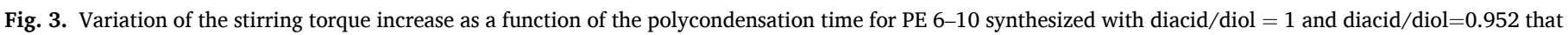
is $5 \mathrm{~mol} \%$ diol excess. $\mathrm{T}=250^{\circ} \mathrm{C}, \mathrm{BuSnOOH}(\mathrm{Sn}=300 \mathrm{ppm})$. 


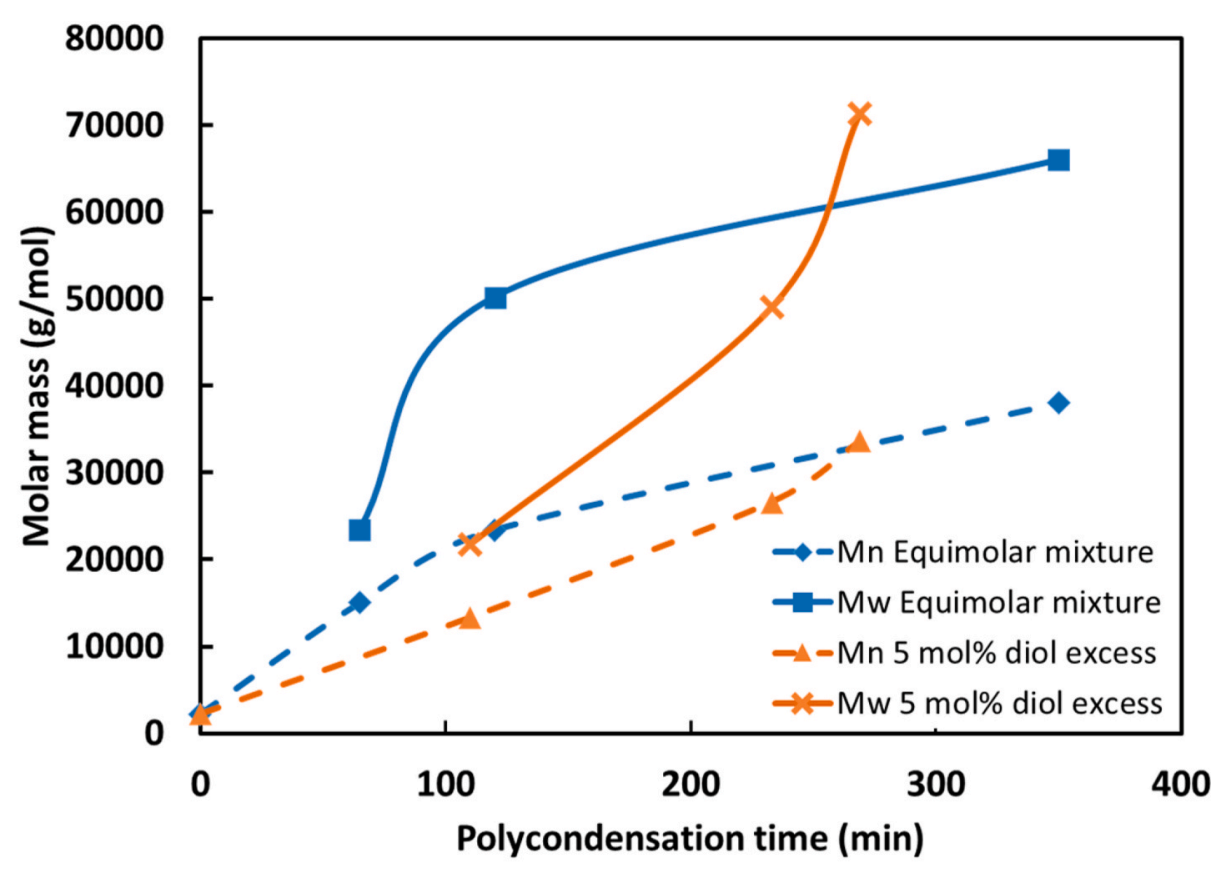

(a)

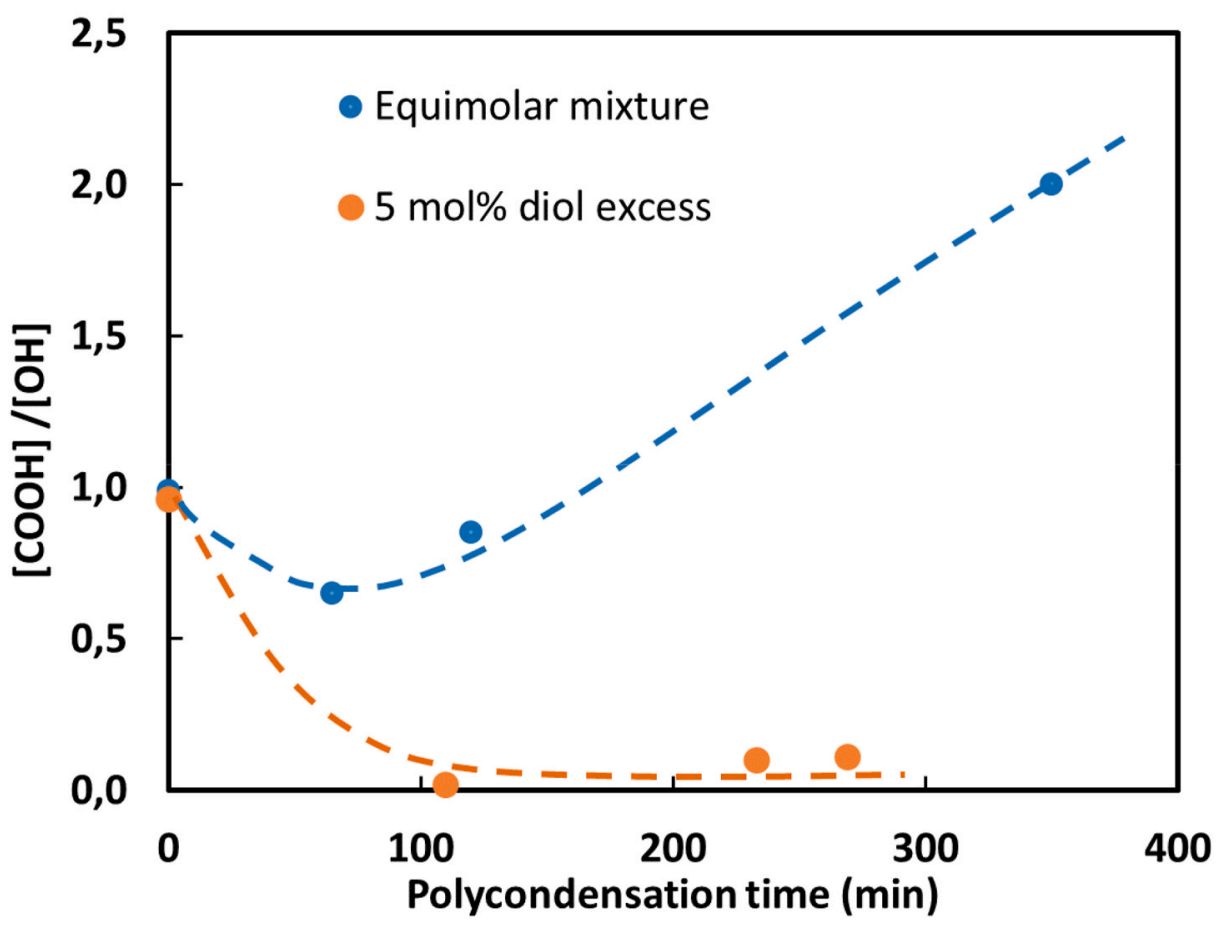

(b)

produced which is much more difficult to eliminate from the reaction medium than water. Therefore, under the initial moderate vacuum the molar mass increases slowly. The acceleration after $200 \mathrm{~min}$ is explained by the high vacuum that is applied at the end of the process which finally leads to the elimination of hexanediol. It can be seen that the molar mass increases sharply between 200 and $270 \mathrm{~min}$. In addition, the degradation is very limited because there are very few acid chain ends, $[\mathrm{COOH}] /[\mathrm{OH}]=0.11$ at $\mathrm{t}=270 \mathrm{~min}$ and polymerization time is reduced ( $270 \mathrm{~min}$ compared to $350 \mathrm{~min}$ ).
Fig. 4. a) Weight average molar mass (full line) and number average molar mass (dotted lines) for $7.5 \mathrm{~L}$ pilot reactor polymerizations stopped at torque $=$ $0.2,5.8$ and $12.1 \mathrm{~N} \mathrm{~m}$. Equimolar monomer mixture (blue symbols $\square$ ) and $5 \mathrm{~mol} \%$ excess diol (orange symbols $\boldsymbol{x} \mathbf{\Delta}$ ). b) Chain ends molar ratio $[\mathrm{COOH}] /[\mathrm{OH}]$. Equimolar monomer mixture (blue symbols ) and $5 \mathrm{~mol} \%$ excess diol (orange symbols ๑). $\mathrm{T}=250{ }^{\circ} \mathrm{C}, \mathrm{BuSnOOH}(\mathrm{Sn}=300 \mathrm{ppm})$. Molar masses are determined by SEC and those at $\mathrm{t}=0$ by ${ }^{1} \mathrm{H}$ NMR spectroscopy. (For interpretation of the references to colour in this figure legend, the reader is referred to the Web version of this article.) 
Table 3

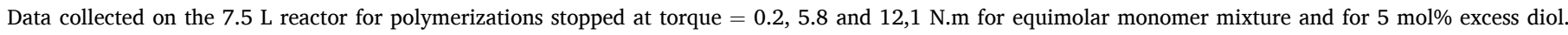
$\left(\mathrm{T}=250{ }^{\circ} \mathrm{C}, \mathrm{BuSnOOH}\right.$ with $\left.\mathrm{Sn}=300 \mathrm{ppm}\right)$.

\begin{tabular}{|c|c|c|c|c|c|c|c|c|c|}
\hline \multirow{2}{*}{$\begin{array}{l}\text { Monomers molar ratio } \\
{[\mathrm{COOH}] /[\mathrm{OH}]}\end{array}$} & \multirow{2}{*}{$\begin{array}{l}\text { Stirring Torque } \\
\quad \Delta \mathrm{C}(\mathrm{Nm})\end{array}$} & \multirow{2}{*}{$\begin{array}{l}\text { Polycondensation time } \\
\text { (min) }\end{array}$} & \multirow{2}{*}{$\begin{array}{l}\mathrm{Mn}^{\mathrm{a}}(\mathrm{g} \\
\left.\mathrm{mol}^{-1}\right)\end{array}$} & \multirow{2}{*}{$\begin{array}{l}\mathrm{Mn}^{\mathrm{b}}(\mathrm{g} \\
\left.\mathrm{mol}^{-1}\right)\end{array}$} & \multirow{2}{*}{$\begin{array}{l}\mathrm{Mw}^{\mathrm{b}}(\mathrm{g} . \\
\left.\mathrm{mol}^{-1}\right)\end{array}$} & \multirow[t]{2}{*}{$\mathrm{Ð}^{\mathrm{b}}$} & \multicolumn{3}{|c|}{ Chain ends of final PE 6-10 } \\
\hline & & & & & & & $\begin{array}{c}{[\mathrm{COOH}]\left(10^{-6}\right.} \\
\left.\mathrm{mol} \mathrm{g}^{-1}\right)\end{array}$ & $\begin{array}{c}{[\mathrm{OH}]\left(10^{-6}\right.} \\
\left.\mathrm{mol} \mathrm{g}^{-1}\right)\end{array}$ & $\begin{array}{c}{[\mathrm{COOH}] /} \\
{[\mathrm{OH}]}\end{array}$ \\
\hline 1 & 0.2 & 65 & 15,000 & 15,800 & 23,000 & 1.5 & 47 & 73 & 0.65 \\
\hline 1 & 5.8 & 120 & 23,500 & 32,000 & 50,000 & 1.6 & 41 & 34 & 0.85 \\
\hline 1 & 12.1 & 350 & 37,500 & 40,000 & 66,000 & 1.7 & 31 & 16 & 2 \\
\hline 0.952 & 0.2 & 130 & 12,500 & 13,300 & 22,000 & 1.7 & 3 & 139 & 0.02 \\
\hline 0.952 & 5.8 & 230 & 24,000 & 26,500 & 49,000 & 1.9 & 6 & 68 & 0.10 \\
\hline 0.952 & 12.1 & 270 & 26,500 & 33,000 & 71,000 & 2.1 & 6 & 60 & 0.11 \\
\hline
\end{tabular}

a ${ }^{1} \mathrm{H}$ NMR spectroscopy.

b SEC.

For alcoholysis reactions, this is less the case because they depend on the accessibility to the catalytic species. This selectivity to short chains may explain the low final dispersity (1.7) observed when an equimolar mixture is used, while the dispersity tends to 2 in the case of the excess of diol.

\subsection{Polymerization in the extruder}

The information collected in the batch reactors were helpful to identify the favorable conditions for extrusion. In the pilot reactor, in the best case the reaction lasted $400 \mathrm{~min}$ to reach a number average molar mass between 26,000 and 43,000 g. $\mathrm{mol}^{-1}$. This polymerization time seems a priori incompatible with extrusion residence times. Fortunately, in the extruder some factors are much more favorable than in a reactor. The heat exchange and mixing capacities of the extruder are an asset. Similarly, the small volume and the rapid renewal of the surfaces of the reaction medium favors the liquid-vapor exchanges essential to chain growth.

In the extruder a crucial issue was to avoid losing monomer/oligomers by evaporation or at least to control the loss so that the acid/ alcohol ratio remains favorable to chain growth. We have seen that acid/ alcohol should range between 1 and 0.952 . From batch reactor experiments we have learn that equimolarity was the best situation to ensure a rapid increase of the molar mass at the very beginning of the process and a small diol excess has also been tested.

\subsubsection{Esterification step in the extruder}

The objective of the esterification step was to rapidly form oligomers of PE 6-10 with chains long enough to avoid losing monomers/oligomers by evaporation. The target value for the oligomers molar mass was a minimum of $1,500 \mathrm{~g} \cdot \mathrm{mol}^{-1}$. Also, the chain-ends molar ratio had to be controlled to enable chain growth by esterification and/or alcoholysis in a second step.

Numerous preliminary experiments were necessary to optimize the operating conditions (screw and temperature profile, feeding conditions, degassing). These intermediate results obtained with the $\mathrm{L} / \mathrm{D}=60$ extruder are not presented here. The best operating parameters set was transferred on the $\mathrm{L} / \mathrm{D}=80$ extruder and the best results are described below.

The $\mathrm{L} / \mathrm{D}=80$ extruder was used with the screw profile designed for esterification (ST 80). It is summarized in Fig. 5. The kneading and reverse-flight sections dominate largely in order to extend the residence time. The flow rate was set at $1.6 \mathrm{~kg} . \mathrm{h}^{-1}$ for hexanediol and $2.6 \mathrm{~kg} . \mathrm{h}^{-1}$ for sebacic acid which corresponds to a diol excess of $5 \mathrm{~mol} \%$. A small excess of diol was necessary to compensate the loss of this more volatile monomer. The rotation speed of the screws was set at $200 \mathrm{rpm}$. The mean residence time was estimated to $7 \mathrm{~min}$.

A vertical feeder was positioned in 37D on the open vent to limit the loss of diol by evaporation. This device that retains the melt in the extruder thanks to its two screws, was thermoregulated. By selecting the appropriate temperature the screws and barrel surface of the feeder acted as a condenser for the diol and allowed the water produced by esterification to be eliminated.
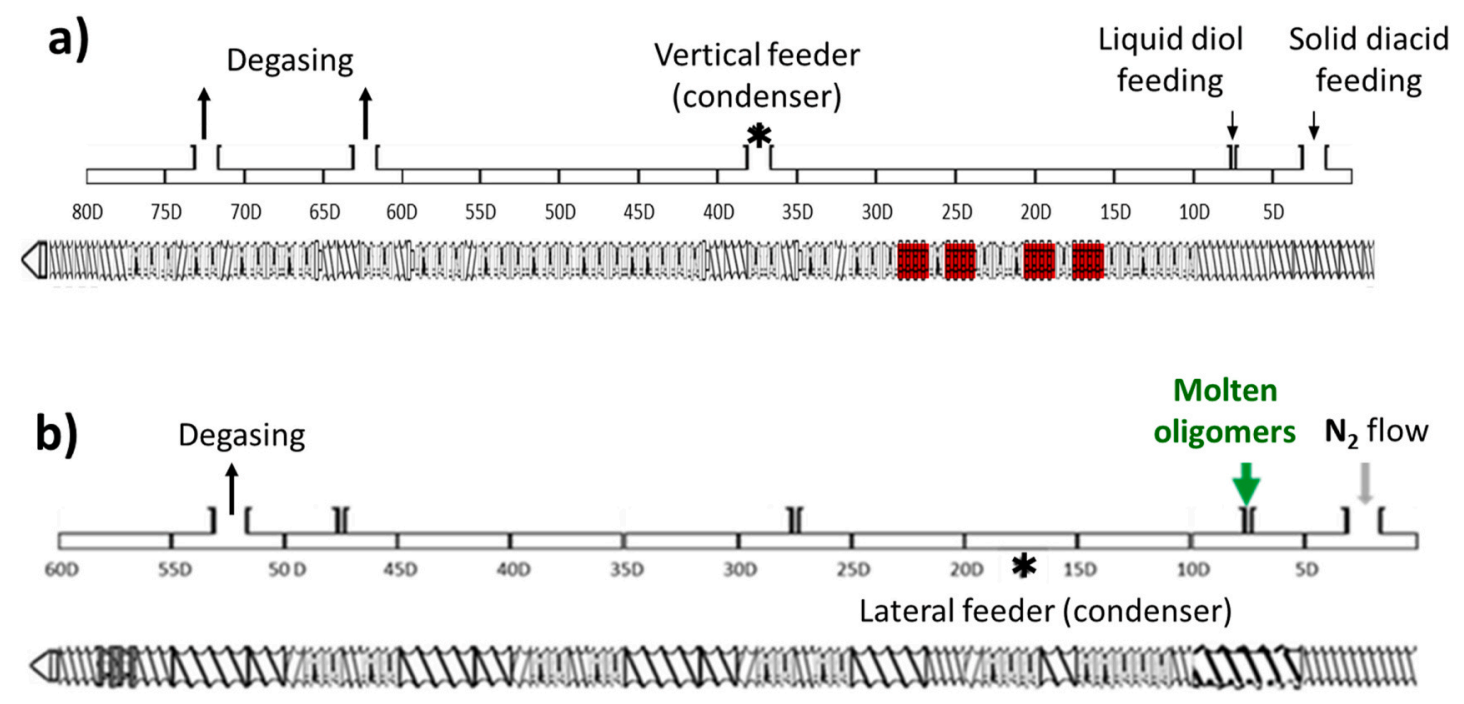

Fig. 5. a) Screw profile $\mathrm{ST} 80$ used for the esterification step (extruder $\mathrm{L} / \mathrm{D}=80$ with $\mathrm{D}=26 \mathrm{~mm}$ ). b) Screw profile used for the transreations step (extruder $\mathrm{L} / \mathrm{D}=60$ with $\mathrm{D}=18 \mathrm{~mm}$ ). 


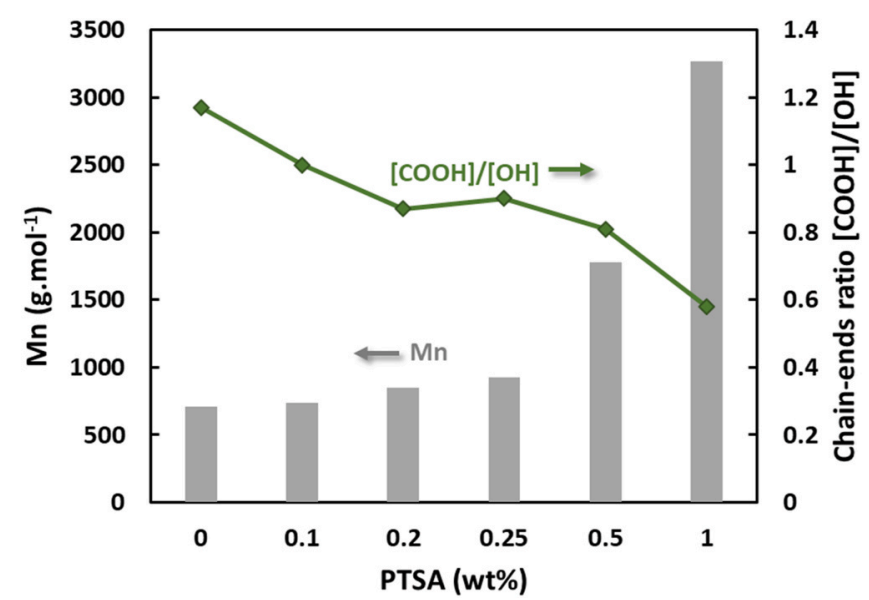

Fig. 6. DPn and chain ends ratio $[\mathrm{COOH}] /[\mathrm{OH}]$ of PE 6-10 oligomers obtained during esterification with PTSA catalyst in the 80D extruder with vertical feeder at $37 \mathrm{D}$ thermoregulated at $100{ }^{\circ} \mathrm{C}$. Temperature profile $=285^{\circ} \mathrm{C}$.

A high extrusion temperature $\left(\mathrm{T}=285^{\circ} \mathrm{C}\right)$ and the use of PTSA as a catalyst were critical parameters. Without catalyst, DPn was around 4-5 and reached 22 with 10,000 ppm PTSA (Fig. 6). The optimum PTSA concentration is in the same range as the one determined from reactor synthesis.

Esterification is therefore feasible in extruder in $7 \mathrm{~min}$ with PTSA catalyst. The other experiments not presented here have demonstrated that the small excess of diol was necessary. However as soon as it exceeded $5 \mathrm{~mol} \%$ the reaction was less effective which confirmed the results obtained with the batch reactor.

\subsubsection{Polycondensation in the extruder}

The polycondensation was carried out with the $\mathrm{L} / \mathrm{D}=60$ extruder. The screw profile was designed with 5 long mixing zones and a short one just before the die (Fig. 5). On the batch reactor a very high vacuum is essential for removing hexanediol formed during alcoholysis but it is very difficult to apply such a vacuum on the extruder as the polymer is very fluid. After exploratory tests and optimizations, a continuous flow of nitrogen and a counter-flow were applied to flush and eliminate the residual water resulting from the continuation of the esterification as well as the hexanediol resulting from the alcoholysis reactions. The extruder was fed with well controlled oligomers prepared by esterification carried out either in the pilot reactor or in the extruder.

The oligomers used during the tests were:

Oligomer A: synthesized in the pilot reactor/equimolar mixture of monomers/no catalyst.

Oligomer B: synthesized in the pilot reactor $/ 5$ mol\% excess diol/

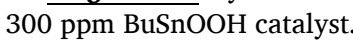

Oligomer C and D: synthesized in extruder $/ 5 \mathrm{~mol} \%$ excess diol/ 10,000 ppm PTSA.

Depending on the situation, the BuSnOOH catalyst was either

Table 4

Characterization of oligomer A before reactive extrusion and characterization of the final PE 6-10. Nitrogen flushing $=3 \mathrm{~m}^{3} \cdot \mathrm{h}^{-1}$ in $2 \mathrm{D}$ with vent opened in 42D. $\mathrm{BuSnOOH}$ with $\mathrm{Sn}=300 \mathrm{ppm}$. Effect of the extrusion temperature.

\begin{tabular}{|c|c|c|c|}
\hline & $\begin{array}{c}\text { Extrusion } \\
\text { temperature }\left({ }^{\circ} \mathrm{C}\right)\end{array}$ & $\begin{array}{l}\mathrm{Mn}^{\mathrm{a}}(\mathrm{g} \\
\left.\mathrm{mol}^{-1}\right)\end{array}$ & $\begin{array}{c}\text { Chain ends ratio }^{a} \\
{[\mathrm{COOH}] /[\mathrm{OH}]}\end{array}$ \\
\hline $\begin{array}{l}\text { Oligomer A feeding } \\
\text { the extruder }\end{array}$ & / & 2800 & 1.13 \\
\hline \multirow[t]{3}{*}{ Final PE 6-10 } & 250 & 6,400 & 1.20 \\
\hline & $250 / 275$ & 8,100 & 1.23 \\
\hline & 275 & 13,000 & 1.53 \\
\hline
\end{tabular}

${ }^{\mathrm{a}}$ Determined with ${ }^{1} \mathrm{H}$ NMR spectroscopy.
Table 5

Characterization of PE 6-10 oligomers before reactive extrusion and characterization of the PE 6-10 obtained. $\mathrm{T}=275^{\circ} \mathrm{C}$. Effect of the type of oligomer fed in the extruder on the final polyester.

\begin{tabular}{lccc}
\hline & $\begin{array}{c}\text { Catalyst added in } \\
\text { extruderBuSnOOH (ppm of } \\
\text { Sn) }\end{array}$ & $\begin{array}{c}\mathrm{Mn}^{\mathrm{a}}(\mathrm{g} . \\
\left.\mathrm{mol}^{-1}\right)\end{array}$ & $\begin{array}{c}\text { Chain ends } \\
\mathrm{ratio}^{\mathrm{a}}[\mathrm{COOH}] / \\
{[\mathrm{OH}]}\end{array}$ \\
\hline $\begin{array}{c}\text { Oligomer A } \\
\text { PE 6-10 obtained } \\
\text { with oligomer A }\end{array}$ & 300 & $\begin{array}{c}2,500 \\
11,200\end{array}$ & $\begin{array}{c}1.22 \\
2.33\end{array}$ \\
\hline $\begin{array}{c}\text { Oligomer B } \\
\text { (BuSnOOH Sn }\end{array}$ & & 3,200 & 0.60 \\
$\begin{array}{c}\text { 300 ppm) } \\
\text { PE 6-10 obtained } \\
\text { with oligomer B }\end{array}$ & 0 & 11,600 & 0.12 \\
\hline $\begin{array}{c}\text { Oligomer C (PTSA } \\
\text { 2000 ppm) }\end{array}$ & & 3,300 & 0.67 \\
PE 6-10 obtained \\
$\begin{array}{c}\text { with oligomer C } \\
\text { PE 6-10 obtained } \\
\text { with oligomer C }\end{array}$ \\
\hline
\end{tabular}

${ }^{\text {a }}$ Determined with ${ }^{1} \mathrm{H}$ NMR.

already present in the oligomers (B) or added and mixed before introduction in the extruder (A, C and D).

The solid oligomers were melted at $\mathrm{T}=165{ }^{\circ} \mathrm{C}$ before injection in the extruder. The mass flow rate was set at $0.3 \mathrm{~kg} . \mathrm{h}^{-1}$, the screw speed at 50 $\mathrm{rpm}$. The average residence time was estimated about $7 \mathrm{~min}$.

The temperature profile was adjusted first with oligomer A (Table 4). The highest temperature, $275{ }^{\circ} \mathrm{C}$ was necessary to increase the molar mass up to $13,000 \mathrm{~g} \mathrm{~mol}^{-1}$ and laid to some degradation as shown by the increase in acidic end groups (from 1.13 to 1.53).

In a second step, oligomers A, B and C were tested with the optimized temperature profile (Table 5).

The molar mass obtained from oligomers A and B were almost similar. However, the ratio of chain ends was different since the starting oligomers did not have the same initial $[\mathrm{COOH}] /[\mathrm{OH}]$ ratio. For oligomer A synthesized with an equimolar mixture of monomers, esterification and alcoholysis reactions were in competition and caused a final excess in acidic end groups. On the other hand, for oligomer B synthesized with a diol excess of $5 \mathrm{~mol} \%$, the chains were predominantly terminated by an alcohol because alcoholysis was dominant and this is a very good point.

The effect of PTSA catalyst may be highlighted when considering PE 6-10 formed with oligomer $C$. The highest increase in molar mass was obtained compared to oligomers A and B $\left(17,000 \mathrm{~g} \mathrm{~mol}^{-1}\right.$ versus 11,200 and 11,600 g.mol ${ }^{-1}$ respectively). PTSA promotes esterification during extrusion in parallel with alcoholysis. Furthermore, increasing the concentration of alcoholysis catalyst from 300 to $600 \mathrm{ppm}$ lead to an increase of the molar mass from 17,000 to $21,600 \mathrm{~g} \cdot \mathrm{mol}^{-1}$.

Finally, a feed rate increased was experimented, feeding the extruder

Table 6

Characterization of PE 6-10 oligomer D before reactive extrusion and characterization of the PE 6-10 obtained for increasing feedrate and adapting nitrogen flow. $\mathrm{T}=275^{\circ} \mathrm{C}, \mathrm{BuSnOOH}(\mathrm{Sn}=300 \mathrm{ppm})$.

\begin{tabular}{ccc}
\hline Feed rate $\left(\mathrm{kg} \cdot \mathrm{h}^{-1}\right)$ & $\begin{array}{c}\mathrm{Mn}^{\mathrm{a}}(\mathrm{g} . \\
\left.\mathrm{mol}^{-1}\right)\end{array}$ & $\begin{array}{c}\text { Chain ends ratio } \\
{[\mathrm{OH}]}\end{array}$ \\
\hline Oligomer D & 3,350 & 0.51 \\
\hline 0.3 & 11,100 & 0.63 \\
0.5 & 9,600 & 0.54 \\
1 & 8,300 & 0.44 \\
2 & 6,800 & 0.41 \\
1 & 9,600 & 0.40 \\
Nitrogen counter-flow in 32D at & & \\
200 L.h & \\
\hline
\end{tabular}

${ }^{\text {a }}$ Determined with ${ }^{1} \mathrm{H}$ NMR spectroscopy. 
with oligomer D prepared in extruder with the same conditions as oligomer C (different batch). The feed rate was increased from $300 \mathrm{~g} \cdot \mathrm{h}^{-1}$ to $500 . \mathrm{g} \mathrm{h}^{-1}, 1 \mathrm{~kg} \cdot \mathrm{h}^{-1}$ and $2 \mathrm{~kg} \cdot \mathrm{h}^{-1}$. An additional nitrogen counter-flow was set on the extruder for the test at $1 \mathrm{~kg} \cdot \mathrm{h}^{-1}$. The characteristics of samples are listed in Table 6 . The higher was the feed rate, the lower the molar mass of PE 6-10 obtained as could be anticipated since the time allowed for reaction was lowered. For $1 \mathrm{~kg} \cdot \mathrm{h}^{-1}$ test, adding a nitrogen flow partially compensated this effect.

\section{Conclusion}

The synthesis of PE 6-10 model polyester was first carried out in classical batch reactors. This synthesis proved to be very sensitive to the alcohol/acid groups ratio. A alcohol/acid ratio close to 1 or in a small excess of diol gave access to short reaction times and high molar mass.

Transferring the process to the extruder required extensive optimization of the screw profiles and extrusion parameters. Control of diol loss and the use of a high concentration of para-toluenesulfonic acid (PTSA) catalyst were essential to undergo esterification. The polymerization proceeded both by esterification and by alcoholysis so the use of $n$-butylhydroxyoxostannane (BuSnOOH) was also necessary.

The overall process was carried out in two extrusion stages with different screw profiles for reasons of experimental ease and for decoupling the steps.

A number average molar mass of $21,600 \mathrm{~g} \cdot \mathrm{mol}^{-1}$ was obtained in the most favorable case. This molar mass was produced in 14 min average residence time while an equivalent $\mathrm{Mn}$ requires more than $400 \mathrm{~min}$ in a batch reactor (reaction time $=$ heating step + esterification + polycondensation). Adjustment of the extrusion operating conditions may be further improved and it is quite reasonable to think that higher molar masses can be produced and/or the required residence time reduced.

The synthesis of polyesters by esterification/polycondensation via reactive extrusion demonstrated its potentialities. In the context of research and development of new polyesters, extrusion would make it possible to explore composition ranges in a much more versatile way and much faster than a batch reactor that allows only one synthesis per day.

\section{Declaration of competing interest}

The authors declare that they have no known competing financial interests or personal relationships that could have appeared to influence the work reported in this paper.

\section{Acknowledgements}

The authors would like to thank the company Setup Performance (France) and the ANRT (France) for financial support. The authors would like to thank the NMR Polymer Center of Institut de Chimie de Lyon (FR5223) for assistance and access to the NMR facilities. And this work has benefited from the facilities and expertise of the Liquid Chromatography Platform (Institut de Chimie de Lyon) for the characterization of polymers. Flavien Mélis is gratefully acknowledged for his work, advices and great involvement in reactive extrusion experiments.

\section{Appendix A. Supplementary data}

Supplementary data to this article can be found online at https://doi. org/10.1016/j.polymer.2021.123644.

\section{References}

[1] M.E. Hyun, S.C. Kim, A study on the reactive extrusion process of polyurethane, Polym. Eng. Sci. 28 (1988) 743-757, https://doi.org/10.1002/pen.760281107.

[2] J.-P. Puaux, P. Cassagnau, G. Bozga, L. Nagy, Modeling of polyurethane synthesis by reactive extrusion, Chem. Eng. Process: Process Intens. 45 (2006) 481-487, https://doi.org/10.1016/j.cep.2005.11.006.
[3] V.W.A. Verhoeven, A.D. Padsalgikar, K.J. Ganzeveld, L.P.B.M. Janssen, A kinetic investigation of polyurethane polymerization for reactive extrusion purposes, J. Appl. Polym. Sci. 101 (2006) 370-382, https://doi.org/10.1002/app.23848.

[4] C. Hopmann, E. Klünker, A. Cohnen, M. Adamy, Chapter 13: reactive extrusion of polyamide 6 with integrated multiple melt degassing. In: Reactive Extrusion: Principles and Applications, Günter Beyer, John Wiley \& Sons, Christian Hopmann, 2017.

[5] A. Wollny, H. Nitz, H. Faulhammer, N. Hoogen, R. Mülhaupt, In situ formation and compounding of polyamide 12 by reactive extrusion, J. Appl. Polym. Sci. 90 (2003) 344-351, https://doi.org/10.1002/app.12577.

[6] P.R. Hornsby, J.F. Tung, K. Tarverdi, Characterization of polyamide 6 made by reactive extrusion. I. Synthesis and characterization of properties, J. Appl. Polym. Sci. 53 (1994) 891-897, https://doi.org/10.1002/app.1994.070530705.

[7] D. Yan, J. Li, J. Li, H. Liu, H. Zhou, G. Shen, Novel polyamide 6/polystyrene in situ microfibrillar blends prepared by anionic polymerization of $\varepsilon$-caprolactam via reactive extrusion, Macromol. Mater. Eng. 301 (2016) 1242-1247, https://doi.org/ 10.1002/mame.201600178.

[8] P. Desbois, M. Kopietz, R. Neuhaus, H. Stawitzki, H.J. Weis, J. Engelmann, Method for the Production of Polyamides in Extruders, US 2010/0190952 A1, 2010.

[9] D. Lagneaux, J. Gimenez, A.-C. Brosse, L. Goujard, H. Sautel, Method for Preparing a Polyamide by Reactice Extrusion, and Extruder Adapted for the Implementation of Such a Method, WO2014016521, 2014. A1.

[10] L. Verny, N. Ylla, F. Da Cruz-Boisson, E. Espuche, R. Mercier, G. Sudre, V. BounorLegaré, Solvent-free reactive extrusion as an innovative and efficient process for the synthesis of polyimides, Ind. Eng. Chem. Res. 59 (2020) 16191-16204, https:// doi.org/10.1021/acs.iecr.0c02881.

[11] R. Narayan, M. Krishnan, J.B. Snook, A. Gupta, P. Dubois, Bulk reactive Extrusion Polymerization Process Producing Aliphatic Ester Polymer Compositions, 1998, p. US5801224A.

[12] S. Jacobsen, H.G. Fritz, P. Degée, P. Dubois, R. Jérôme, Polylactide (PLA)-a new way of production, Polym. Eng. Sci. 39 (1999) 1311-1319, https://doi.org/ 10.1002/pen.11518.

[13] J.-M. Raquez, R. Narayan, P. Dubois, Recent advances in reactive extrusion processing of biodegradable polymer-based compositions, Macromol. Mater. Eng. 293 (2008) 447-470, https://doi.org/10.1002/mame.200700395.

[14] R. Mincheva, S. Narayana Murthy Chilla, R. Todd, B. Guillerm, J. De Winter, P. Gerbaux, O. Coulembier, P. Dubois, J.-M. Raquez, Reactive extrusion and magnesium (II) N-heterocyclic carbene catalyst in continuous PLA production, Polymers 11 (2019) 1987, https://doi.org/10.3390/polym11121987.

[15] H. Wautier, L. Detournay, M. Kaszacs, Process for the Continuous Manufacture of Poly- Epsilon -caprolactones, US5656718, A), 1997.

[16] J. Gimenez, M. Boudris, P. Cassagnau, A. Michel, Control of bulk $\varepsilon$-caprolactone polymerization in a twin-screw extruder, Polym. React. Eng. 8 (2000) 135-157, https://doi.org/10.1080/10543414.2000.10744545.

[17] A.V. Machado, V. Bounor-Legare, N.D. Goncalves, F. Melis, P. Cassagnau, A. Michel, Continuous polymerization of epsilon-caprolactone initiated by titanium phenoxide in a twin-screw extruder, J. Appl. Polym. Sci. 110 (2008) 3480-3487, https://doi.org/10.1002/app.28850.

[18] S. Spinella, M. Ganesh, G. Lo Re, S. Zhang, J.-M. Raquez, P. Dubois, R.A. Gross, Enzymatic reactive extrusion: moving towards continuous enzyme-catalysed polyester polymerisation and processing, Green Chem. 17 (2015) 4146-4150, https://doi.org/10.1039/C5GC00992H.

[19] R.R. Burch, S.R. Lustig, M. Spinu, Synthesis of cyclic oligoesters and their rapid polymerization to high molecular weight, Macromolecules 33 (2000) 5053-5064, https://doi.org/10.1021/ma000278b.

[20] W. Balhoul, V. Bounor-Legaré, F. Fenouillot, P. Cassagnau, EVA/PBT nanostructured blends synthesized by in situ polymerization of cyclic cBT (cyclic butylene terephthalate) in molten EVA, Polymer 50 (2009) 2527-2534, https:// doi.org/10.1016/j.polymer.2009.03.055.

[21] E.V. Gouinlock, H.W. Marciniak, M.H. Shatz, E.J. Quinn, R.R. Hindersinn, Preparation and properties of copolyesters polymerized in a vented extruder, J. Appl. Polym. Sci. 12 (1968) 2403-2413, https://doi.org/10.1002/ app.1968.070121103.

[22] R. Shogren, S. Gonzalez, J.L. Willett, D. Graiver, G. Swift, Preparation of sorbitol citrate polyesters by reactive extrusion and application as inhibitors of calcium carbonate precipitation, J. Biobased Mater. Bioenergy 1 (2009) 229-237, https:// doi.org/10.1166/jbmb.2007.027.

[23] P.F.H. Harmsen, M.M. Hackmann, H.L. Bos, Green building blocks for bio-based plastics, Biofuels Bioproducts and Biorefining 8 (2014) 306-324, https://doi.org/ 10.1002/bbb.1468.

[24] A.M. Allgeier, N. Desilva, E. Korovessi, C. Menning, J.C. Ritter, S.K. Sengupta, Process for Preparing 1, hexanediol, 2013, p. 6. WO 2013101980A1.

[25] E.F. Izard, The effect of chemical composition on selected physical properties of linear polymers, J. Polym. Sci. 8 (1952) 503-518, https://doi.org/10.1002/ pol.1952.120080507.

[26] J.J. O'malley, W.J. Stauffer, Synthesis and characterization of isomeric polyesters based on sebacic acid and hexanediols, J. Polym. Sci., Polym. Chem. Ed. 12 (1974) 865-874, https://doi.org/10.1002/pol.1974.170120416.

[27] E. Armelin, M.T. Casas, J. Puiggali, Structure of poly(hexamethylene sebacate), Polymer 42 (2001) 5695-5699, https://doi.org/10.1016/S0032-3861(01)000350 .

[28] M. Siotto, E. Sezenna, S. Saponaro, F. DegliInnocenti, M. Tosin, L. Bonomo, V. Mezzanotte, Kinetics of monomer biodegradation in soil, J. Environ. Manag. 93 (2012) 31-37, https://doi.org/10.1016/j.jenvman.2011.08.018.

[29] N. Jacquel, F. Freyermouth, F. Fenouillot, Rousseau, A. Rousseau, J.-P. Pascault, P. Fuertes, R. Saint-Loup, Synthesis and properties of poly(butylene succinate): 
efficiency of different transesterification catalysts, J. Polym. Sci., Part A: Polym. Chem. 49 (2011) 5301-5312, https://doi.org/10.1002/pola.25009.

[30] S. Legrand, N. Jacquel, H. Amedro, R. Saint-Loup, M. Colella, J.-P. Pascault, F. Fenouillot, A. Rousseau, Isosorbide and tricyclodecanedimethanol for the synthesis of amorphous and high tg partially biobased copolyesters, ACS Sustain. Chem. Eng. 8 (2020) 15199-15208, https://doi.org/10.1021 acssuschemeng.0c04679.
[31] P.F. Erhardt, W.C. Richards, Un Nouveau Révélateur Pour Toner D’impression, 1974. FR 2222680A1.

[32] F. Farachi, M. Foa, T. Milizia, Simplified Method of Producing Biodegradable Aliphatic Polyesters, 2003. US 6562939.

[33] P.J. Flory, Principles of Polymer Chemistry, Cornell university press, Ithaca, New York, 1953.

[34] G. Odian, Principles of Polymerization, fourth ed., John Wiley and sons, 2004. 